\title{
Identification of a predominant isolate of Mycobacterium tuberculosis using molecular and clinical epidemiology tools and in vitro cytokine responses
} M Kaushal Sharma*1,2, A Al-Azem¹, J Wolfe2, E Hershfield ${ }^{3,4}$ and A Kabani1,4

Address: ${ }^{1}$ Clinical Microbiology, Health Sciences Center, Winnipeg, MB, Canada, ${ }^{2}$ National Reference Centre for Mycobacteriology, National Microbiology Laboratories, Health Canada, 1015 Arlington Street, Winnipeg, Canada, ${ }^{3}$ Provincial Tuberculosis Registry, Health Sciences Center, Winnipeg, Canada and ${ }^{4}$ Faculty of Medicine, University of Manitoba, Winnipeg, Canada

Email: M Kaushal Sharma* - meenu_sharma@hc-sc.gc.ca; A Al-Azem - umalmoua@cc.umanitoba.ca; JWolfe - joyce_wolfe@hc-sc.gc.ca; E Hershfield - ehersh@ccu.umanitoba.ca; A Kabani - akabani@hsc.mb.ca

* Corresponding author

Published: 8 April 2003

BMC Infectious Diseases 2003, 3:3
Received: 18 November 2002

Accepted: 8 April 2003

This article is available from: http://www.biomedcentral.com/I47I-2334/3/3

(C) 2003 Sharma et al; licensee BioMed Central Ltd. This is an Open Access article: verbatim copying and redistribution of this article are permitted in all media for any purpose, provided this notice is preserved along with the article's original URL.

\begin{abstract}
Background: Tuberculosis (TB) surveillance programs in Canada have established that TB in Canada is becoming a disease of geographically and demographically distinct groups. In 1995, treaty status aboriginals from the province of Manitoba accounted for $46 \%$ of the disease burden of this sub-group in Canada. The TB incidence rates are dramatically high in certain reserves of Manitoba and are equivalent to rates in African countries. The objective of our study was to identify prevalent isolates of Mycobacterium tuberculosis in the patient population of Manitoba using molecular epidemiology tools, studying the patient demographics associated with the prevalent strain and studying the in vitro cytokine profiles post-infection with the predominant strain.
\end{abstract}

Methods: Molecular typing was performed on all isolates available between 1992 to I997. A clinical database was generated using patient information from Manitoba. THP-I cells were infected using strains of $M$. tuberculosis and cytokine profiles were determined using immunoassays for cytokines IL-I $\beta$, IL-I0, IL-I2, IFN- $\gamma$ and TNF- $\alpha$.

Results: In Manitoba, 24\% of the disease burden is due to a particular M. tuberculosis strain (Typel). The strain is common in patients of aboriginal decent and is responsible for at least $87 \%$ of these cases. Cytokine assays indicate that the Typel strain induces comparatively lower titers of IL-I $\beta$, IFN- $\gamma$ and TNF- $\alpha$ in infected THP-I cells as compared to H37Ra and H37Rv strains.

Conclusion: In Manitoba, Typel strain is predominant in TB patients. The majority of the cases infected with this particular strain are newly active with a high incidence of respiratory disease, positive chest radiographs and pulmonary cavities. In vitro secretion of IL-I $\beta$, IFN- $\gamma$ and TNF- $\alpha$ is suppressed in Typel infected culture samples when compared to H37Ra and H37Rv infected cells.

Background

Epidemiology of tuberculosis
Tuberculosis $(\mathrm{TB})$ infects one-third of the world population and causes approximately 3 million deaths annually 
[1-4]. The average incidence rate for tuberculosis is 5.9 per 100,000 population in Canada and 9.2 per 100,000 population in the Canadian province of Manitoba $[3,5]$. In Canada, the majority of TB cases in most provinces are attributed to immigration. Of all the TB cases in each of the provinces of Ontario, British Columbia and Quebec, foreign born cases represent majority of the cases $(81 \%$, $60 \%$ and $48 \%$ of the cases, respectively) while foreign born cases represent only $29 \%$ of the total TB cases in Manitoba [3]. In Manitoba, the composition of TB patients is distinctly different from that of other Canadian provinces as the majority of TB cases are among Canadian-born individuals, with the highest incidence among treaty (registered) aboriginals (48.4 per 100,000 overall, with rates as high as 496.3 per 100,000 in select communities) [3]. 'Aboriginals' or 'first nations' describe the indigenous Canadians and their descendants, encompassing those registered as status aboriginals, Métis, Innu and Intuit individuals that may live on or off reserves. In the past few decades, incidence rates of TB have declined in every sub-population, however rates among Canadian-born treaty individuals in Manitoba (48.4 per 100,000) are still more than ten times higher than for non-treaty subgroup $(3.3$ per 100,000$)$ and more than two times higher than for the foreign-born subgroup (22.0 per 100,000) [3-6]. Canadian surveillance studies have shown that TB is prevalent in geographically and demographically distinct groups, such as, foreign-born and aboriginal individuals [5]. These groups have sustained a steady level of incidence and are in need of targeted TB control measures, with treaty status sub-population contributing to the majority of the current burden of incident cases [5]. The incidence rate of $\mathrm{TB}$ among treaty status aboriginals $(48.4$ per 100,000$)$ was five times higher than the overall provincial rate $(9.2$ per 100,000$)$ and eight times higher than the national rate of $\mathrm{TB}$ (5.9 per $100,000)$. The incidence rate of TB in treaty status aboriginals is probably an underestimate as the number of aboriginal individuals that have not claimed treaty status is unknown.

Manitoba has a population of 1.15 million of which $78.1 \%$ are Canadian-born (CB) non-treaty, $8.9 \%$ are treaty aboriginals, and the remainder (13\%) are foreign-born (Statistics Canada census, 2002). The majority of Manitoba residents live in the capital city of Winnipeg $(685,500)$. There are 139 reserves in Manitoba; reserves are tracts of land whose legal title is held by the Federal Crown and which has been set apart for use and benefit of a particular First Nation community (Statistics Canada census, 2002, Province of Manitoba, 2000). All of the TB cases in the province are reported to TB control program that monitors provincial TB patient registry, hospitals, clinics and diagnostic TB laboratories in Manitoba [5].
Currently available molecular diagnostic techniques such as Restriction Fragment Length Polymorphism (RFLP) using the insertion sequence IS6110, secondary probes (pTBN12), and spoligotyping, permit strain identification within species with a higher degree of specificity compared to traditional methods [7-11]. These techniques help to confirm or identify the chain of transmission and the distribution of strain clusters, allowing insight into the molecular evolution of the species [7,12-14]. The most widely used method is IS6110-RFLP typing of Mycobacterium tuberculosis (M. tuberculosis) which relies on repetitive DNA insertion sequence with a length of $1361 \mathrm{bp}$ and is specific to the M. tuberculosis complex $[7,10]$. In our laboratory, IS6110-RFLPtyping was performed on 479 patient isolates and we analyzed the predominant RFLP patterns among these isolates.

\section{Host responses to tuberculosis}

TB infection is a competitive balance between the bacterium, M. tuberculosis trying to establish itself within the host tissues and host cellular defense mechanisms striving to overcome the infection. The progression of the disease is governed by both host genetic factors and interactions between the host and parasite [15-18]. Host defenses depend mostly on cell mediated immunity, primarily $\mathrm{T}$ lymphocytes and macrophages [16]. Macrophages are the first cells to encounter $M$. tuberculosis in lungs of the host and they react to the parasite by producing a distinct pattern of cytokines including; Interleukin-1 (IL-1), IL-2, IL10 , IL-12, tumor necrosis factor-alpha (TNF- $\alpha$ ) and interferon-gamma (IFN- $\gamma)[16,19]$. The pro-inflammatory cytokines, such as IL-1, IL-12, TNF- $\alpha$ and IFN- $\gamma$ as well as anti-inflammatory cytokine IL-10 were analyzed in this study [19-21]. In this study, the patient demographic and geographic factors associated with the prevalent clinical isolates were studied. To investigate whether this prevalent $M$. tuberculosis strain was virulent, we examined the in vitro growth rate of these bacilli and the cytokine responses in THP-1 cells following infection with M. tuberculosis strains.

\section{Methods DNA Fingerprinting}

479 isolates were available from 610 TB patients (19921997) at The Mycobacteriology Laboratory, Health Sciences Centre, Winnipeg. The mycobacterial genomic DNA was extracted and purified using conventional methods $[11,22]$. The digestion of genomic mycobacterial DNA using PvuII was carried out as described by Van Embden et al [22] with a few modifications $[10,12]$. The digested DNA was transferred onto the nylon membrane, probed overnight with DIG-labeled IS6110 probe at $65^{\circ} \mathrm{C}$ and exposed to X-ray film for 15-20 minutes. Fingerprint pattern images were captured using GelDoc (Bio-Rad, Hercules, CA) and analyzed using Molecular Analyst 
Software-fingerprinting version 1.1 (Bio-Rad). Computer assisted phylogenetic analysis was employed to characterize strains and assess banding pattern similarities. Numerical designations were arbitrarily assigned to strains according to their prevalence in the population under study.

\section{Data collection}

A total of $115 \mathrm{~TB}$ patient records were screened for this study between 1992-1997 and were obtained from the Provincial TB Registry, Manitoba. The data fields such as age, sex, race, origin, disease diagnosis, chest X-ray, the presence of cavitary disease and residential location were extracted from the patient records and the information was entered into a database. This data was blinded, allowing data analysis while maintaining the patient confidentiality.

\section{Immunology}

\section{Bacterial strains}

M. tuberculosis strain H37Ra (ATCC 25177), H37Rv (ATCC 25618) and Type1 were cultured for 6 weeks on Middlebrook 7H10 agar media [23]. Bacilli were harvested at mid-log phase and adjusted to $1 \times 10^{7}$ cells per $\mathrm{ml}$ in phosphate buffered saline (PBS). Colony counts and purity checks were performed on these cultures [24].

\section{Culture of macrophages}

Human mononuclear cell line, THP-1 (ATCC TIB-202), was used in our experiments. THP-1 cells are phagocytic in nature and can be induced to differentiate into macrophage-like cells [25]. The cells were cultured in RPMI1640 media (Sigma, ON, Canada) supplemented with $10 \%$ fetal bovine serum (FBS, Sigma) and 1\% streptomycin-penicillin antibiotic (Sigma). Cells were stained with trypan blue (Sigma) and the number of viable cells were determined using a hemacytometer $[23,25]$.

\section{Monocyte stimulation}

THP- 1 cells $\left(2 \times 10^{6}\right.$ cells $)$ grown in RPMI media supplemented with 5\% FBS and without antibiotic, were infected with $2 \times 10^{7}$ colony forming units of either of H37Ra, H37Rv and Type1 M. tuberculosis strains. Uninfected PBS was used as a negative control. Colony counts of mycobacteria were determined at each time point post-infection by subculturing serial dilutions of the cultures onto Middlebrook $7 \mathrm{H} 10$ plates. Supernatants were collected at different time intervals i.e., 0.25, 2, 4, 6, 8, 24, 48, 72 hours post-infection by centrifugation at $3000 \times \mathrm{g}$ for 20 minutes at $15^{\circ} \mathrm{C}$ and were then aliquoted and stored at $20^{\circ} \mathrm{C}$ until used $[20,24]$.

\section{Enzyme Linked Immunosorbent Assay}

Enzyme Linked Immunosorbent Assay (ELISA) was carried out in triplicate for each infection using commercially available antibody pairs for cytokines IL-12, IL-1 $\beta$, IFN- $\gamma$, TNF- $\alpha$ and IL-10 in accordance to manufacturer's instructions $^{\circledR}$ \& D Systems, Minneapolis). Each assay was run with a negative control (PBS) and blank samples (according to manufacturer's instructions). The average zero standard optical density was subtracted from different standard and sample optical densities. Sample concentrations were calculated using a standard curve. The results were expressed as amounts of cytokine in picograms per milliliter $(\mathrm{pg} / \mathrm{ml})$. The average values were calculated from six independent trials which were each analyzed in triplicate.

\section{Statistical analysis}

Data was statistically analyzed using SAS software (version 7.0, Cary, North Carolina). Results were derived from six independent experiments, each carried out in triplicate. Cytokine results were correlated at each time point using a non-parametric correlation coefficient. Each immunological (cytokine) variable was analyzed using a two-way ANOVA correlating group and time interaction, followed by least square means multiple comparisons with bonferroni corrections.

\section{Results \\ Typel Epidemiology}

Between 1992 and 1997, there were 610 TB positive patients in Manitoba. There are 194 M. tuberculosis strains isolated from 479 patients from Manitoba and the top 5 strains are Type1, Type5, Type2, Type 72 , Type 1 that are responsible for $24 \%, 5 \%, 4.6 \%, 4.2 \%$ and $2 \%$ of the total TB cases, respectively. The predominant group of isolates (115/479 cases; $24 \%$ ) showed a similar banding pattern, which we referred to as fingerprint 'Type1'. As 1 in 4 patients were infected with Type1, we screened patient records for cases which depicted this fingerprint pattern. Of all Type 1 cases reported in the province of Manitoba, Winnipeg, the capital city of Manitoba alone accounted for $70 / 115$ cases $(60.8 \%)$ of the cases. Among Type 1 patients residing in cities, $98.5 \%$ of the individuals lived in the city of Winnipeg. In areas other than cities, 93\% of the Type1 patients lived on aboriginal reserves. Winnipeg and aboriginal reserves appear to be reservoirs of Type1 strain. The majority of the Type 1 cases were newly active (91/115 cases; 79\%). This strain causes disease in the younger groups with an age range of $21-50$ years (84/115 cases; $73 \%)$. Within this group, patients with an age range of $31-40$ yrs (31/115 cases; $26.9 \%$ ) are at the most risk of developing disease due to this strain. Infection from this strain appears to be more prevalent among males (73/115 cases; $63 \%$ ). The majority of treaty and non-treaty status aboriginal people (100/115 cases; $87 \%$ ) had this Type1 strain isolated from their cultures. Of a total of 100 aboriginal cases, $85(85 \%)$ had treaty status and $15(15 \%)$ were non-treaty status aboriginals. Radiograms of the 


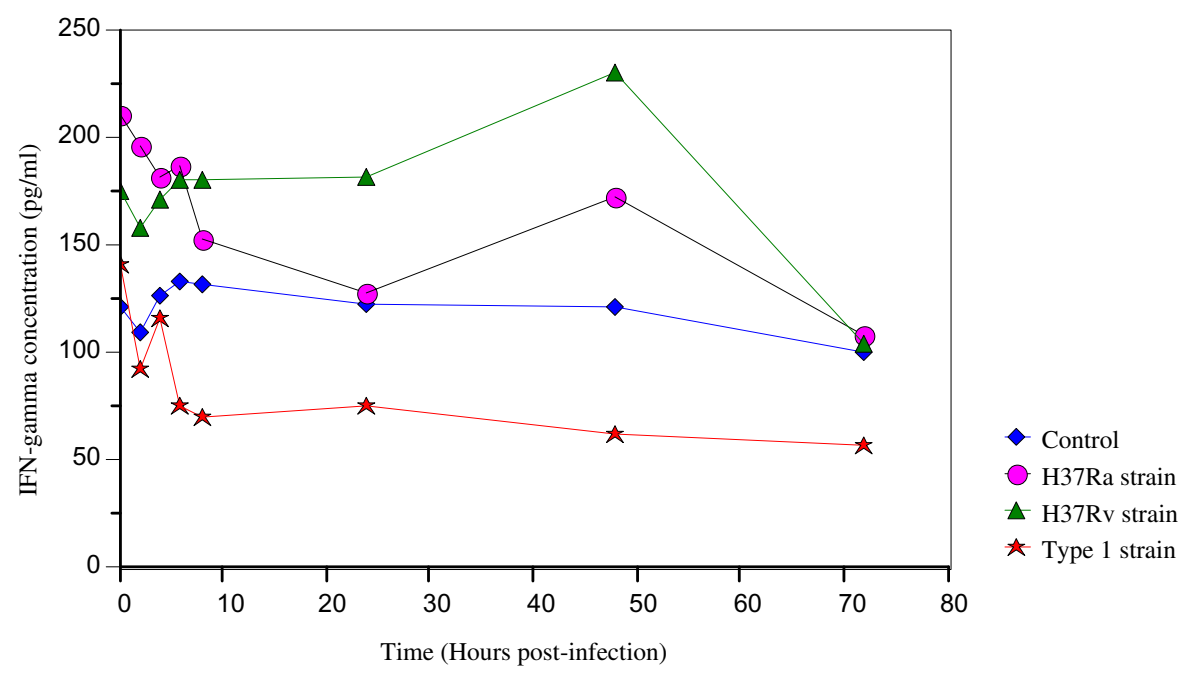

\section{Figure I}

IFN- $\gamma$ secretion in THP-I cells infected with H37Ra, H37Rv and the Typel strains of M. tuberculosis.

patients show that many of Type1 cases exhibited respiratory disease (104/115 cases; $90 \%)$ and some (22/115 cases; $19 \%$ ) had developed pulmonary cavities.

\section{In vitro cytokine production post-infection}

We examined the in vitro response of human THP-1 monocytes to infection with $\mathrm{M}$. tuberculosis H37Rv, H37Ra and the Type1 strain (See methods). Colony counts (measured in $\mathrm{cfu}$ ) were obtained post-infection at $0.25,2,4,6,8,24,48$ and 72 hrs to determine the log difference in colony forming units over time. Differences in the cfu $\log _{10}$ values $\left[\log _{10}(\max )-\log _{10}(\min )\right]$ of $M$. tuberculosis strains at $0.25,2,4,6,8,24,48$ and 72 hrs postinfection were 0.2 for H37Ra, 0.15 for H37 Rv and 0.16 for Type1 strain. At any time point, differences in the cfu $\log _{10}$ values between H37Ra, H37Rv and Type1 were also insignificant (Difference in $\log _{10}$ values $\leq 0.15$ ).

Levels of IL-12, IL-1 $\beta$, IFN- $\gamma$, TNF- $\alpha$ and IL-10 were measured in M. tuberculosis infected cell cultures. The levels of the forementioned cytokines were determined at $0.25,2$, $4,6,8,24,48$ and 72 hrs post-infection in order to observe any change of profile during this time period.

IFN- $\gamma$

Secretion of IFN- $\gamma$ was highest in supernatants of H37Rv infected cells $(\mathrm{p}<0.05)$ in comparison to cells infected with H37Ra or Type1 strains (Fig. 1). IFN- $\gamma$ secretion was consistently low in Type1 infected cultures, compared to the control (6-72 hrs post-infection; p < 0.033), H37Ra infected cells $(0.25-72$ hrs post infection; $p<0.02)$ and 


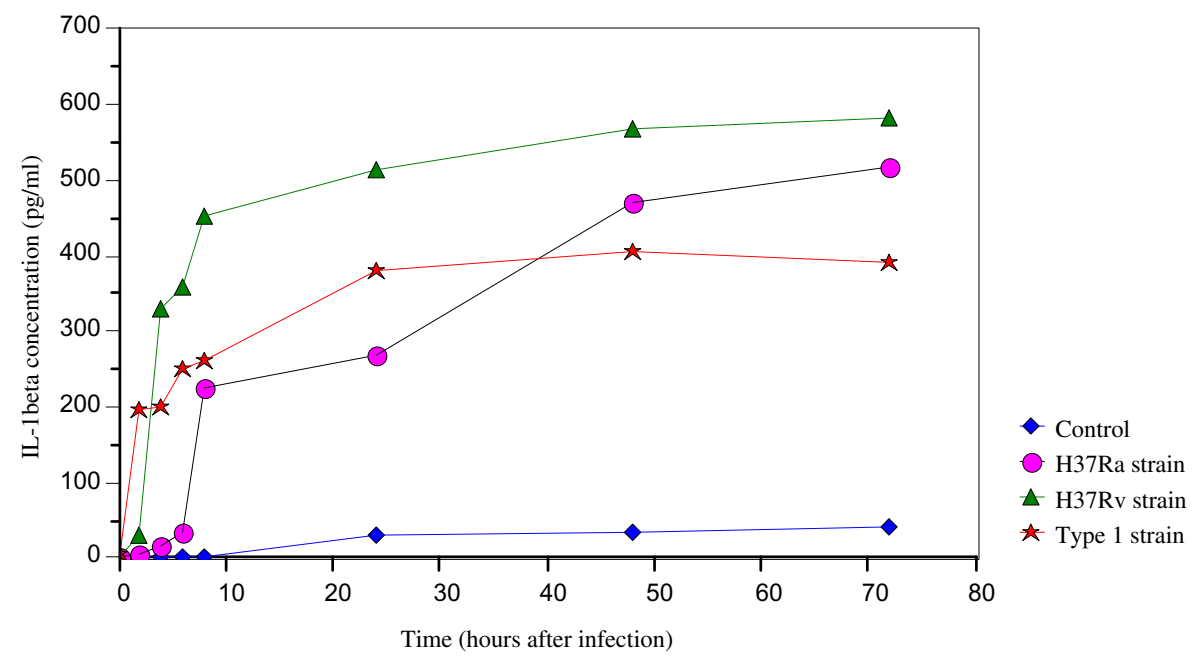

Figure 2

IL-I $\beta$ secretion in THP-I cells infected with H37Ra, H37Rv and the Typel strains of M. tuberculosis.

H37Rv infected cells $(0.25-48$ hrs post infection; $\mathrm{p}<$ $0.02)$. These results show that the expression of IFN- $\gamma$ was suppressed in cells infected with the Type1 strain (Fig. 1).

\section{IL-I $\beta$}

IL-1 $\beta$ levels were significantly lower in supernatants infected with the Type1 compared to those from supernatants infected with the $\mathrm{H} 37 \mathrm{Rv}$ strain $(2-72$ hrs post infection; $\mathrm{p}<0.0001)$. In comparison to the Type1, H37Ra infected cultures showed a sustained increase in IL-1 $\beta$ secretion at 24 hours post-infection $(\mathrm{p}<0.01)$ (Fig. 2).

\section{TNF- $\alpha$}

TNF- $\alpha$ secretion was higher in supernatants of H37 Rv infected cells $(8-72$ hrs post-infection, $\mathrm{p}<0.005)$ than in supernatants of cultures infected with other strain types and controls (Fig. 3). Secretion of TNF- $\alpha$ in Type1 infected cells was higher than for H37Ra infected cells. TNF- $\alpha$ secreted was stable from 8-72 hours inType1 infected cells (Fig. 3).

\section{IL-IO}

IL-10 secretion in Type1 infected cells was elevated ( $\mathrm{p}<$ 0.05 ) at $0.25-4$ hrs post-infection as compared to secretion in H37Ra and H37Rv infected cells and controls (Fig. $4)$. The level of IL-10 in the Type 1 infected cells were statistically insignificant at other time points as compared to cells infected with H37Ra and H37Rv. 


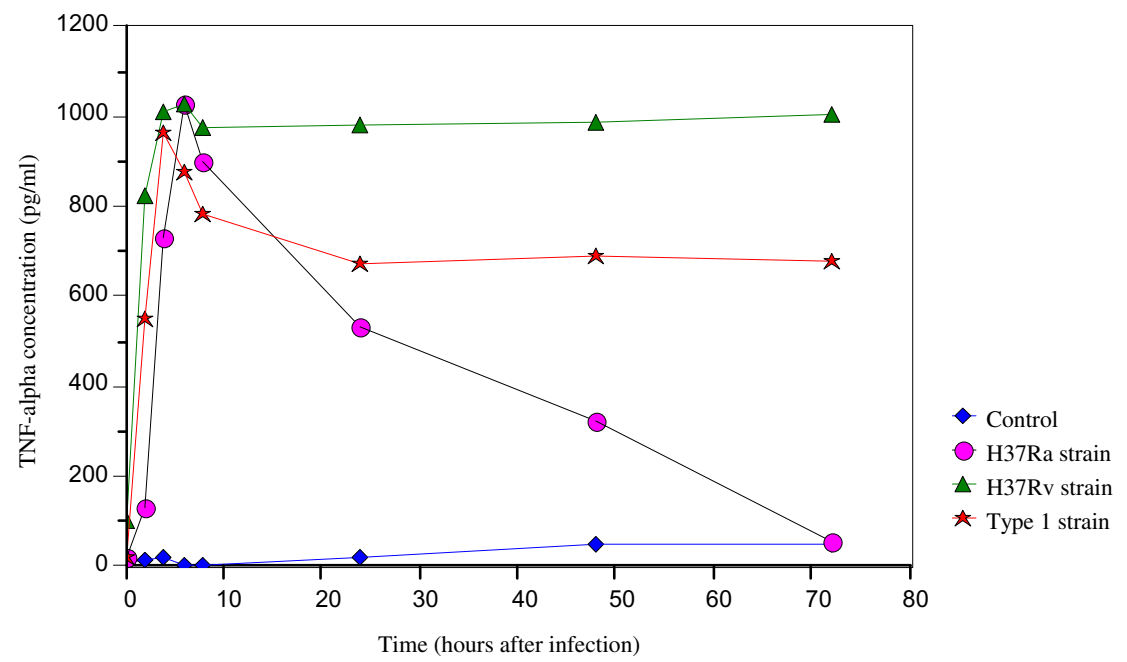

Figure 3

TNF- $\alpha$ secretion in THP-I cells infected with H37Ra, H37Rv and the Typel strains of M. tuberculosis.

\section{IL-I 2}

Levels of IL-12 were undetectable in all infected cells at all given time points.

\section{Discussion \\ Epidemiology}

Different $M$. tuberculosis strains have different rates of transmission in a population. IS6110-RFLP analysis has shown that some strains of $M$. tuberculosis are more capable of causing disease outbreaks than other strains $[11,26]$. Our epidemiological investigations have shown that the Type 1 strain causes cluster outbreaks with a high rate of active infection and accounts for $24 \%$ of all TB cases in Manitoba. This strain is prevalent among infected individuals of aboriginal decent (87\%) [3]. Until recently, it was believed that the high prevalence of this strain was secondary to socioeconomic factors. However, these fac- tors alone do not account for the high prevalence of Type 1 strain and the high incidence of patients displaying newly active disease, respiratory disease, positive radiograms and pulmonary cavities. A study by our collaborators has also demonstrated the occurrence of central nervous system (CNS) TB may be strain dependent and that Type1 strain was significantly associated with the number of CNS TB positive cases [27]. A recent study conducted by Manca et al has shown that different clinical isolates may elicit different responses in vivo and may be designated as virulent or hypervirulent $[28,29]$. We were interested in studying Type 1 strain as it is responsible for approximately one in four cases of TB in Manitoba and 9 of 10 TB cases in the aboriginals of Manitoba. The probability that this strain has a higher potential to cause disease in infected subjects must be explored further using different methods such as in vitro and in vivo host responses and in vivo sur- 


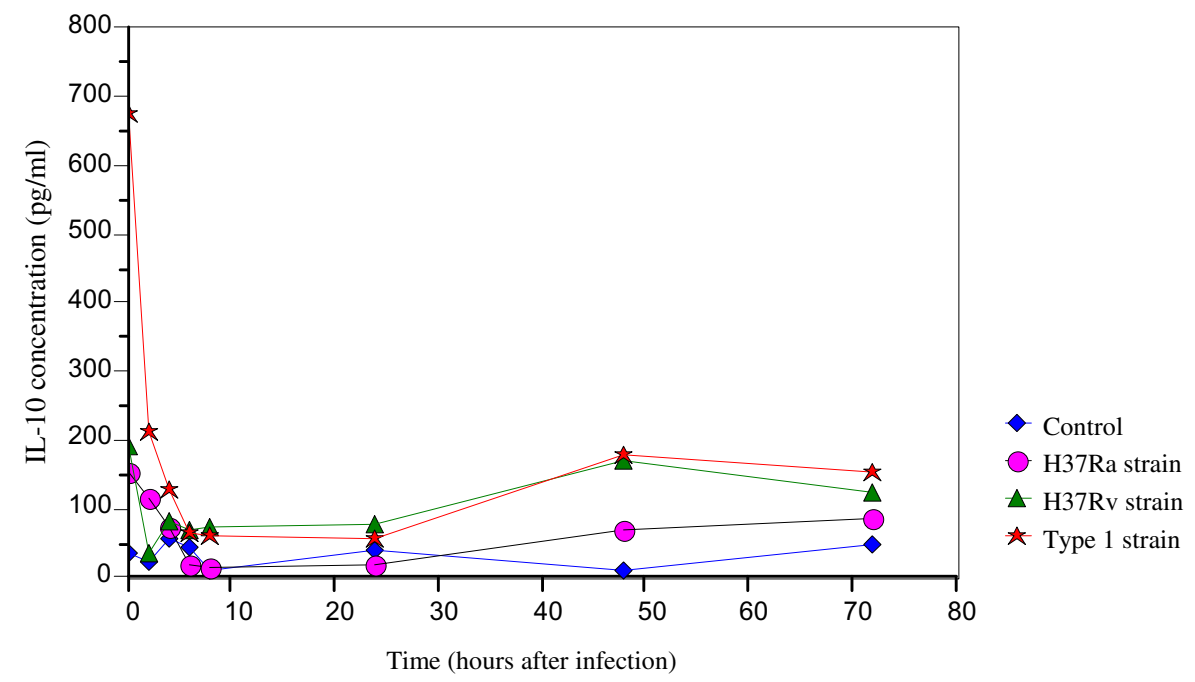

\section{Figure 4}

IL-IO secretion in THP-I cells infected with H37Ra, H37Rv and the Typel strains of M. tuberculosis.

vival studies. In this study, we studied in vitro host response in cells infected with Type1 by estimating the secretion levels of four pro-inflammatory and an anti-inflammatory cytokines over a period of time (0.25-72 hrs).

\section{Mycobacterial Growth}

The colony count data shows that the growth of all M.tuberculosis strains was similar throughout the experiment. The doubling time for M. tuberculosis varies from 20-30 hrs, and since our THP1 infection experiments were carried out over a total of $72 \mathrm{hrs}$, the bacilli could only have gone through 2-3 cycles of replication. In addition, $M$. $t u$ berculosis requires specialized growth media (Lowenstein Jensen, Middlebrook 7H10, 7H9, BACTEC 12B etc.) and since our infection experiments were carried out using a non-specific M. tuberculosis growth media (RPMI), it may explain the insignificant difference in the growth $\left(\log _{10}\right.$ values) of $M$. tuberculosis strains.

\section{Cytokine responses}

Cytokines play a key role in the success of the host immune response against mycobacterial infection and in the pathogenesis of TB. In TB, the host responses are provided by $T$ cells and macrophages $[16,19,20]$. Indeed, macrophages are the first cells of the immune system that are exposed to $M$. tuberculosis. They act by engulfing the bacilli, producing proteolytic enzymes, presenting mycobacterial antigens to $\mathrm{T}$ cells and producing a characteristic pattern of cytokines that regulate the immune system and mediate many of clinical manifestations of TB [16]. We used a human THP-1 monocytic cell line in vitro and carried out mycobacterial infections with H37Ra, H37Rv, Type1 strains and PBS control. THP-1 cells are phagocytic in na- 
ture and can differentiate into mature cells that function as macrophages that are capable of producing cytokines such as IL-1, IL-8, IL-6, IL-10, IL-12p40 and TNF- $\alpha$ [25].

Our results demonstrate that there is a specific pattern of cytokines secreted by infected THP-1cells. Titers for most of the pro-inflammatory cytokines as IFN- $\gamma$, IL-1 $\beta$ and TNF- $\alpha$ were highest in cells infected with H37Rv strain. Type 1 infected cells expressed lower amounts of these cytokines as compared to H37Ra and H37 Rv infected cells. Although IL-12 is an important pro-inflammatory cytokine that favors Th1 host immune responses and is directly responsible for the outcome of the TB infection, it was not detected in sufficient amounts in our system $[30,31]$. There are several possible explanations for this observation. Firstly, perhaps M. tuberculosis organism itself is unable to induce sufficient amounts of IL-12 in THP-1 cells $[30,31]$. Secondly, negative stimulators of IL-12 production such as IL-10 and IL-4 may counteract pro-inflammatory effects of IL-12 [31]. Finally, we cannot exclude the possibility that IL-12 secretion may be mycobacterial dose dependent. Other methods such as RT-PCR may be used to detect IL-12 levels more effectively than the method used in this study.

It is known that IFN- $\gamma$ enhances the antimicrobial activity of macrophages through increased production of hydrogen peroxide and nitric oxide metabolites, while inhibiting the proliferation of Th2 cells and the secretion of Type 2 cytokines [32-34]. IFN- $\gamma$ secretion was depressed in cells infected with the Type 1 and hence these low levels were insufficient to induce the macrophages to secrete IL-12 (Fig. 1). Both IFN- $\gamma$ and TNF- $\alpha$ are required for protective host immunity to TB infection [34-38] and the production of $[30,31]$ low expression levels of IFN- $\gamma$ are likely responsible for the impaired protective immune cascade to a greater extent in Type 1 infected cells than H37 Rv infected cells. Furthermore, mixed cell culture experiments containing T-lymphocytes may be a more favourable model to study IFN- $\gamma$ production as T-lymphocytes are a more important cellular source of IFN- $\gamma$ than monocytes. Studies using animal models may provide a better experimental model to study this cytokine.

IL-1 is produced upon stimulation by M. tuberculosis cell wall components and mycobacterial proteins [16]. IL-1 secretion upregulates T-cell expression of IL-2 and IL-2 receptors, induces macrophages to produce other pro-inflammatory cytokines such as IL- 6 and TNF- $\alpha$ and may contribute to development of fever $[16,36]$. The comparatively lower concentrations of IL-1 $\beta$ in Type 1 infected cells may have resulted in lesser TNF- $\alpha$ secretion (Fig. 2), thus providing a more stable environment for the strain to propagate or reside within the host cell.
TNF- $\alpha$ secretion was detected for all the strains from $0.25-$ $8 \mathrm{hrs}$ but thereafter was higher in H37Rv and Type 1 infected cells (Fig. 3). Similar titers of TNF- $\alpha$ at $0.25-8$ hrs. postinfection with all $M$. tuberculosis strain can be attributed to M. tuberculosis as well as its cell wall components and proteins. In vitro and in vivo studies from other laboratories have shown that mycobacterial components induce higher amounts of TNF- $\alpha$ in virulent $M$. tuberculosis strains as compared to avirulent strains $[16,26]$. This phenomenon was evident in our experiments from cells infected with virulent strains (24-72 hrs of post infection). However, TNF- $\alpha$ secretion does not complement secretion pattern of other pro-inflammatory cytokines under investigation in Type 1 infected cultures. As TNF- $\alpha$ exhibits both protective immunity, in terms of anti-mycobacterial activity and development of granulomas and pathological effects, including symptoms such as fever and wasting. It is perhaps best to study this cytokine in vivo using animal models whereby a distinction could be made as to which effect is predominant $[16,21]$.

Anti-inflammatory cytokines, such as IL-10, suppress production of the pro-inflammatory cytokines such as IL-12. This process of downregulation of pro-inflammatory cytokines could prove to be deleterious to the host [19]. IL10 , an anti-inflammatory cytokine, inhibits pro-inflammatory cytokine synthesis by monocytes and macrophages [20,39]. Following infection, IL-10 levels in Type1 infected cells were high and subsequently were the similar for H37Ra and H37Rv infected cells (Fig. 4). Similar findings have been demonstrated with other $M$. tuberculosis strains in both in vitro and in vivo studies using animal models as well as in clinical studies [20,35,40].

Upon infection, host cells come into contact with mycobacterial components such as LAM and mycobacterial proteins of molecular weight 20 and $46 \mathrm{kDa}$ and secrete IL- 1 and TNF- $\alpha$. TNF- $\alpha$ is also produced by other mycobacterial proteins of molecular weight 44,58, $65 \mathrm{kDa}$ $[15,21,30,37]$. Compared to other strains under investigation, Type1 infected cells produced lower levels of IL-1 which may have lead to the ineffective host immune response, also resulting in lesser bacillary elimination in these cells. On the other hand, high levels of TNF- $\alpha$ are secreted in host cells infected with virulent strains of $M$. tuberculosis and this data is consistent with TNF- $\alpha$ secretion in Type 1 infected cells $[15,26]$. TNF- $\alpha$ along with other pro-inflammatory cytokines, such as IFN- $\gamma$, activates the macrophages to produce inducible nitric oxide synthase and reactive nitrogen intermediates, which cause reduction of mycobacterial growth but fails to eliminate the pathogen $[21,30,33,37]$. Contrary to pro-inflammatory cytokines, anti-inflammatory cytokines act by downregulating host immune response and limiting host tissue injury and are primarily produced upon infection by $M$. 
tuberculosis [16,20,41]. Excessive IL-10 production at 0.25-4 hrs post-infection may have contributed towards loss of control of infection [20,35,40]. Supportive evidence has shown that elevated levels of TNF- $\alpha$ and IL-10 have been detected in patients with lung TB $[20,35,39,40]$. TB disease is better controlled when the host rapidly develops pro-inflammatory cytokine response in infected cells. On the other hand, disruption of the balance between pro- and anti-inflammatory cytokines by absence or suppression of pro-inflammatory cytokine response and predominance of immuno-suppressive cytokines, as depicted by Type 1 infected cells, may be associated with early development of disease. If these results are replicated in vivo and are correlated with disease progression, they may better explain the predominance and virulence of Type 1 strain in the Manitoba.

\section{Conclusion}

The pathogenesis of TB depends on a combination of $M$. tuberculosis virulence factors and host factors. Results from this study indicate that Type 1 strain has a unique epidemiology as well as a specific cytokine profile, which confers it the ability to modulate host immune response in its favour. These factors may explain the propensity of the Type1 strain in Manitoba, especially among its aboriginals. These findings must be confirmed in vivo using mouse models which will help us to better understand the pathogenesis of the M. tuberculosis Type1 strain. We are currently studying the in vivo survival rate, clearance or non clearance of infection and immunological responses of mice infected with Type 1 and other clinical strains. This would not only provide evidence of strain related virulence but the immunological profiles could also be used to modulate host immune response to enhance therapy of TB.

\section{List of abbreviations used \\ IL: Interleukin}

\section{TB: Tuberculosis}

Type1 strain: M. tuberculosis Type1 strain

IFN- $\gamma$ : Interferon gamma

TNF- $\alpha$ : Tumor necrosis factor alpha

\section{Competing interests}

None declared.

\section{Authors's contributions}

EH is the authorized individual to collect data from TB patients and has official permission for archived information. AA created the database and compiled the patient information. JW cultured all the M. tuberculosis isolates and performed RFLP. MS conducted cytokine experiments, compiled all experimental and clinical data and prepared the manuscript. AK was the directory of this study and also provided salary funds and space for this study.

\section{Acknowledgments}

This work was supported by operating funds from The Dr. H T Paul Thorlakson Foundation Fund, University of Manitoba, Winnipeg, Canada. We would like to thank Sherrie Kelly for her editorial comments.

\section{References}

I. Fanning EA Globalization of tuberculosis [editorial; comment] CMAJ 1998, I58:6II-6I2

2. Raviglione MC, Sudre P, Rieder HL, Spinaci S and Kochi A Secular trends of tuberculosis in western Europe Bull World Health Organ 1993, 7 I(3-4):297-306

3. Al-Azem A, Elliot L, Hershfield E, Blackwood K and Kabani A Conventional and Molecular Epidemiology of Tuberculosis in Manitoba Int J Tuberc Lung Dis 2002,

4. Al-Azem AA, Hershfield ES, Sharma M, Wolfe J, Macmorran J, Hoban DJ and Kabani A Clinical and Molecular Epidemiology of Tuberculosis in Manitoba Community-Acquired Infections and Related Epidemiological Studies 2000, 585-585

5. Long R, Njoo H and Hershfield E Tuberculosis: 3. Epidemiology of the disease in Canada CMAJ 1999, 160:1 I85-1190

6. Long R, Sutherland K, Kunimoto D, Cowie R and Manfreda J The epidemiology of tuberculosis among foreign-born persons in Alberta, Canada, 1989-1998: identification of high risk groups Int J Tuberc Lung Dis 2002, 6:6 I5-62I

7. Cohn DL and O'Brien RJ The use of restriction fragment length polymorphism (RFLP) analysis for epidemiological studies of tuberculosis in developing countries Int J Tuberc Lung Dis 1998, 2:16-26

8. Small PM, Hopewell PC, Samir MD, Singh P, Paz A, Parsonnet J, Ruston DC, Gisela BS, Schecter F, Daley CL and Schoolnik G A Population-Based Study Using Conventional and Molecular Methods New England Journal of Medicine 9940, 330:1703-1709

9. Clarridge JE III, Shawar RM, Shinnick TM and Plikaytis BB Largescale use of polymerase chain reaction for detection of Mycobacterium tuberculosis in a routine mycobacteriology laboratory J Clin Microbiol I993, 3 I:2049-2056

10. van-Soolingen D, Qian L, de-Haas PE, Douglas JT, Traore H, Portaels $F$, Oing HZ, Enkhsaikan D, Nymadawa $P$ and van-Embden JD Predominance of a single genotype of Mycobacterium tuberculosis in countries of east Asia J Clin Microbiol I995, 33:3234-3238

II. van-Soolingen D, Hermans PW, de-Haas PE, Soll DR and van-Embden JD Occurrence and stability of insertion sequences in Mycobacterium tuberculosis complex strains: evaluation of an insertion sequence-dependent DNA polymorphism as a tool in the epidemiology of tuberculosis J Clin Microbiol I99I, 29:25782586

12. Chevrel DD, Abderrahman A, Haltiti R, Koubaji H, Gicquel B and Dellagi $K$ Large-scale DNA fingerprinting of Mycobacterium tuberculosis strains as a tool for epidemiological studies of tuberculosis J Clin Microbiol I 993, 3 I:2446-2450

13. Eisenach KD, Crawford JT and Bates JH Genetic Relatedness among Sttrains of the Mycobacterium tuberculosis Complex Am Rev Respir Dis 1986, 1065-1068

14. Soini H, Pan X, Teeter L, Musser JM and Graviss EA Transmission dynamics and molecular characterization of Mycobacterium tuberculosis isolates with low copy numbers of IS6 II 10 Journal Of Clinical Microbiology 1901, 39:2 17-221

15. Barnes PF, Chatterjee D, Abrams JS, Lu S, Wang E, Yamamura M, Brennan PJ and Modlin RL Cytokine production induced by Mycobacterium tuberculosis lipoarabinomannan. Relationship to chemical structure J Immunol 1992, I 49:54I-547

16. Barnes PF and Modlin RL Human cellular immune responses to Mycobacterium tuberculosis Curr Top Microbiol Immunol 1996, 215:197-219 
17. Skamene E, Schurr E and Gros P Infection genomics: Nramp I as a major determinant of natural resistance to intracellular infections Annu Rev Med 1998, 49:275-287

18. Qureshi ST, Skamene E and Malo D Comparative genomics and host resistance against infectious diseases Emerg Infect Dis 1999 , 5:36-47

19. Lucey DR, Clerici M and Shearer GM Type I and type 2 cytokine dysregulation in human infectious, neoplastic, and inflammatory diseases Clin Microbiol Rev 1996, 9:532-562

20. Elliott AM, Hurst T], Balyeku MN, Quigley MA, Kaleebu P, French N, Biryahwaho B, Whitworth JA, Dockrell HM and Hayes RJ The immune response to Mycobacterium tuberculosis in HIV-infected and uninfected adults in Uganda: application of a whole blood cytokine assay in an epidemiological study Int J Tuberc Lung Dis 1999, 3:239-247

2I. Flesch IE and Kaufmann SH Activation of tuberculostatic macrophage functions by gamma interferon, interleukin-4, and tumor necrosis factor Infect Immun 1990, 58:2675-2677

22. van-Embden JD, Cave MD, Crawford JT, Dale JW, Eisenach KD, Gicquel B, Hermans P, Martin C, McAdam R and Shinnick TM Strain identification of Mycobacterium tuberculosis by DNA fingerprinting: recommendations for a standardized methodology [see comments] J Clin Microbiol 1993, 3 I:406-409

23. Zimmerli S, Edwards S and Ernst JD Selective receptor blockade during phagocytosis does not alter the survival and growth of Mycobacterium tuberculosis in human macrophages $\mathrm{Am}$ Respir Cell Mol Biol 1996, I 5:760-770

24. Fulton SA, Johnsen JM, Wolf SF, Sieburth DS and Boom WH Interleukin- $I 2$ production by human monocytes infected with $M y-$ cobacterium tuberculosis: role of phagocytosis Infect Immun |996, 64:2523-2531

25. Aso H, Yoshite O, Tomioka Y, Rose MT and Mizugaki M A 63 kDa tumor necrosis factor inhibitor released from a human monocytic leukemia cell line, THP-I Microbiol Immunol 1999, 43:53-59

26. Valway SE, Sanchez MPC, Shinnick TF, Orme I, Agerton T, Hoy D, Jones $\mathrm{S}$, Westmoreland $\mathrm{H}$ and Onorato $\mathrm{M}$ An outbreak involving extensive transmission of a virulent strain of Mycobacterium tuberculosis N Engl J Med 1998, 338:633-638

27. Arvanitakis Z, Long RL, Hershfield ES, Manfreda J, Kabani A, Kunimoto $D$ and Power $C M$. tuberculosis molecular variation in CNS infection: evidence for strain-dependent neurovirulence $\mathrm{Neu}$ rology 1998, 50:1827-1832

28. Manca C, Tsenova L, Barry CE, Bergtold A, Freeman S, Haslett PA, Musser JM, Freedman VH and Kaplan G Mycobacterium tuberculosis CDCI55I induces a more vigorous host response in vivo and in vitro, but is not more virulent than other clinical isolates I Immunol 1999, I 62:6740-6746

29. Manca C, Tsenova L, Bergtold A, Freeman S, Tovey M, Musser JM, Barry CE III, Freedman VH and Kaplan G Virulence of a Mycobacterium tuberculosis clinical isolate in mice is determined by failure to induce Th I type immunity and is associated with induction of IFN-alpha/beta Proc Natl Acad Sci U S A 200I, 98:5752-5757

30. Flesch IE, Hess JH, Huang S, Aguet M, Rothe J, Bluethmann $\mathrm{H}$ and Kaufmann SH Early interleukin I 2 production by macrophages in response to mycobacterial infection depends on interferon gamma and tumor necrosis factor alpha J Exp Med 1995 |81:|6|5-|62|

31. Romani L, Puccetti $P$ and Bistoni $F$ Interleukin- $I 2$ in infectious diseases Clin Microbiol Rev 1997, I 0:61 I-636

32. Chan J, Xing Y, Magliozzo RS and Bloom BR Killing of virulent Mycobacterium tuberculosis by reactive nitrogen intermediates produced by activated murine macrophages J Exp Med 1992, I75: IIII-1122

33. Flesch IE and Kaufmann SH Mechanisms involved in mycobacterial growth inhibition by gamma interferon-activated bone marrow macrophages: role of reactive nitrogen intermediates Infect Immun 1991, 59:3213-3218

34. Flynn JL, Chan J, Triebold KJ, Dalton DK, Stewart TA and Bloom BR An essential role for interferon gamma in resistance to $\mathrm{My}$ cobacterium tuberculosis infection J Exp Med 1993, I 78:2249. 2254

35. Chensue SW, Warmington KS, Ruth JH, Lincoln P and Kunkel SL Cytokine function during mycobacterial and schistosomal antigen-induced pulmonary granuloma formation. Local and regional participation of IFN-gamma, IL-I0, and TNF Immunol 1995, I 54:5969-5976

36. Cooper AM, Dalton DK, Stewart TA, Griffin JP, Russell DG and Orme IM Disseminated tuberculosis in interferon gamma gene-disrupted mice J Exp Med 1993, I 78:2243-2247

37. Flynn JL, Goldstein MM, Chan J, Triebold KJ, Pfeffer K, Lowenstein CJ, Schreiber R, Mak TW and Bloom BR Tumor necrosis factor-alpha is required in the protective immune response against Mycobacterium tuberculosis in mice Immunity 1995, 2:56|-572

38. Johnson BJ and McMurray DN Cytokine gene expression by cultures of human lymphocytes with autologous Mycobacterium tuberculosis-infected monocytes Infect Immun 1994 62: $1444-1450$

39. Bogdan C, Vodovotz $Y$ and Nathan $C$ Macrophage deactivation by interleukin I0 I Exp Med I99I, I 74: I549-I555

40. Zhang M, Gong J, Yang Z, Samten B, Cave MD and Barnes PF Enhanced capacity of a widespread strain of Mycobacterium tuberculosis to grow in human macrophages J Infect Dis 1999 , 179: $1213-1217$

4I. Barnes PF and Wizel B Type I cytokines and the pathogenesis of tuberculosis American Journal Of Respiratory And Critical Care Medicine 2000, I6I:1773-1774

\section{Pre-publication history}

The pre-publication history for this paper can be accessed here:

http://www.biomedcentral.com/1471-2334/3/3/prepub
Publish with Bio Med Central and every scientist can read your work free of charge

"BioMed Central will be the most significant development for disseminating the results of biomedical research in our lifetime. "

Sir Paul Nurse, Cancer Research UK

Your research papers will be:

- available free of charge to the entire biomedical community

- peer reviewed and published immediately upon acceptance

- cited in PubMed and archived on PubMed Central

- yours - you keep the copyright

Submit your manuscript here:

http://www.biomedcentral.com/info/publishing_adv.asp
BioMedcentral 